\title{
Honokiol Inhibits Osteoclast Differentiation and Function in Vitro
}

\author{
Shin-ichi Hasegawa, ${ }^{a}$ Takayuki Yonezawa, ${ }^{b, d}$ Jae-Yong Ahn, ${ }^{a}$ Byung-Yoon Cha, ${ }^{b}$ Toshiaki Teruya, ${ }^{b}$ \\ Masamichi TAKAmI, ${ }^{c}$ Kazumi YAGASAKI, ${ }^{d, e}$ Kazuo NAGAI, ${ }^{a, b}$ and Je-Tae Woo ${ }^{*, a, b, d}$ \\ ${ }^{a}$ Department of Biological Chemistry, Chubu University; ${ }^{b}$ Research Institute for Biological Functions, Chubu University; \\ 1200 Matsumoto, Kasugai, Aichi 487-8501, Japan: ' ${ }^{c}$ Department of Biochemistry, School of Dentistry, Showa University; \\ 1-5-8 Hatanodai, Shinagawa, Tokyo 142-8555, Japan: ${ }^{d}$ Department of Nutriproteomics, Graduate School of Medicine, \\ The University of Tokyo; 7-3-1 Hongo, Bunkyo, Tokyo 113-0033, Japan: and ${ }^{e}$ Division of Agriscience and Bioscience, \\ Institute of Symbiotic Science and Technology, Tokyo University of Agriculture and Technology; 3-5-8 Saiwai, Fuchu, \\ Tokyo 183-8509, Japan.
}

Received November 6, 2009; accepted November 28, 2009; published online December 22, 2009

\begin{abstract}
Honokiol, a neolignan, is a physiologically active component of kouboku (Magnolia obovata), a herb used in traditional Chinese medicine. This study investigated the effects of honokiol on the differentiation and function of osteoclasts induced by receptor activator of nuclear factor- $\kappa$ B ligand (RANKL). Honokiol markedly inhibited RANKL-induced tartrate-resistant acid phosphatase (TRAP) activity and the formation of TRAP-positive multinucleated cells in both bone marrow-derived monocytes and RAW264 cells. In experiments to elucidate its mechanism of action, honokiol was found to suppress RANKL-induced phosphorylation of p38 mitogen-activated protein kinase (MAPK), extracellular signal-regulated kinase (ERK), and c-Jun N-terminal kinase (JNK). The RANKL-induced expressions of c-Fos and nuclear factor of activated T cells-c1 (NFATc1), which are crucial transcriptional factors for osteoclastogenesis, were also reduced by treatment with honokiol. Furthermore, honokiol induced disruption of the actin rings in mature osteoclasts (mOCs) without affecting the cell viability and suppressed osteoclastic pit formation on dentin slices. Taken together, these results suggest that honokiol inhibits osteoclast differentiation by suppressing the activation of MAPKs (p38 MAPK, ERK and JNK), decreasing the expressions of c-Fos and NFATc1, and attenuates bone resorption by disrupting the actin rings in mOCs. Therefore, honokiol could prove useful for the treatment of bone diseases associated with excessive bone resorption.
\end{abstract}

Key words honokiol; osteoclast; mitogen-activated protein kinase; c-Fos; nuclear factor of activated T cells-c1; bone resorption

Bone homeostasis is maintained by the balance between the bone-forming activity of osteoblasts and the bone-resorbing activity of osteoclasts. ${ }^{1)}$ Excessive osteoclastic bone resorption results in bone destructive disorders such as osteoporosis. Osteoclasts are multinucleated cells that differentiate from hematopoietic precursors and are capable of resorbing mineralized bone. ${ }^{2)}$ Receptor activator of nuclear factorkappa B (NF- $\kappa$ B) ligand (RANKL), a member of the tumor necrosis factor (TNF) family produced by osteoblasts and stromal cells, is an essential factor for osteoclast differentiation and function. ${ }^{3,4)}$ Tartrate-resistant acid phosphatase (TRAP) is a marker enzyme for osteoclasts. RANKL induces the formation of TRAP-positive multinucleated cells $\left(\mathrm{TRAP}^{+} \mathrm{MNCs}\right)$ in cultures of bone marrow cells (BMCs) in the presence of macrophage colony-stimulating factor (M-CSF) without requiring osteoblasts or stromal cells. ${ }^{5,6}$ RAW264 cells are also known to differentiate into osteoclasts in the presence of RANKL. ${ }^{5,7,8)}$ Compounds that inhibit osteoclast differentiation and/or function are useful for treating or preventing bone diseases characterized by excessive bone resorption.

We screened various compounds of natural origin for their abilities to affect osteoclast differentiation, and identified honokiol as a promising candidate. Honokiol, a neolignan, is an active ingredient of kouboku (stem bark of Magnolia obovata), an herb used in traditional Chinese medicine. ${ }^{9)}$ It is known to have many physiological activities, including anti-inflammatory, anti-allergic, anti-platelet, and anti-tumor properties. ${ }^{10-15)}$ However, the effects of honokiol on osteoclastic bone resorption processes have not previously been investigated in detail. In the present study, we evaluated the effects of honokiol on osteoclast differentiation, function and survival, and determined a possible mechanism of action.

\section{MATERIALS AND METHODS}

Reagents Honokiol was obtained from Wako Pure Chemical Industries Ltd. (Osaka, Japan). Its chemical structure is shown in Fig. 1. Recombinant human transforming growth factor (TGF)- $\beta$, fast red-violet LB salt and naphthol AS-MX phosphate were purchased from Sigma-Aldrich Fine Chemicals (St. Louis, MO, U.S.A.). Recombinant murine MCSF and recombinant human RANKL were obtained from PeproTech EC Ltd. (London, England). PD98059 was obtained from Calbiochem (La Jolla, CA, U.S.A.). Minimum essential medium $\alpha(\alpha$-MEM) was purchased from Gibco (Grand Island, NY, U.S.A.). Anti-phospho-p38 mitogen-activated protein kinase (MAPK) (Thr180/Tyr182), anti-phospho-extracellular signal-regulated kinase (ERK), anti-phospho-c-Jun N-terminal kinase (JNK) (Thr183/Tyr185), antip38 MAPK, anti-ERK, anti-JNK and anti-glyceraldehyde-3phosphate dehydrogenase (GAPDH) antibodies were purchased from Cell Signaling Technology (Danvers, MA, U.S.A.). An anti-inhibitor of NF- $\kappa \mathrm{B}$ (I $\kappa \mathrm{B})$ antibody was purchased from Calbiochem. An anti-c-Fos-antibody was

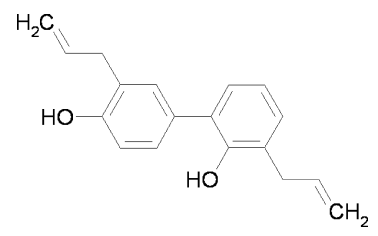

Fig. 1. Structure of Honokiol

$\mathrm{C}_{18} \mathrm{H}_{18} \mathrm{O}_{2}(\mathrm{MW}=266.33)$. 
obtained from Santa Cruz Biotechnology (Santa Cruz, CA, U.S.A.). An anti-nuclear factor of activated $\mathrm{T}$ cells-c1 (NFATc1) antibody was purchased from BD Biosciences (San Jose, CA, U.S.A.). Alexa Fluor 488-conjugated phalloidin was purchased from Molecular Probes Inc. (Eugene, OR, U.S.A.). 4-6-Diamidino-2-phenylindole (DAPI) was purchased from Dojindo (Kumamoto, Japan). Horseradish peroxidase-conjugated donkey anti-rabbit IgG and horseradish peroxidase-conjugated sheep anti-mouse IgG were obtained from GE Healthcare (Piscataway, NJ, U.S.A.). All other chemical reagents were purchased from Wako Pure Chemical Industries Ltd. or Sigma-Aldrich Fine Chemicals unless otherwise stated.

Animals This experimental animal study was approved by the Animal Experiment Committee of Chubu University. The mice were maintained in accordance with the guidelines of the Animal Experiment Committee of Chubu University.

Osteoclast Differentiation BMCs were isolated from 46-week-old ddY mice (SLC Inc., Shizuoka, Japan) as described previously. $\left.{ }^{6}\right)$ The BMCs were washed twice, resuspended in $\alpha$-MEM containing $10 \%$ inactivated fetal bovine serum (FBS) and incubated for $24 \mathrm{~h}$ with M-CSF $(10 \mathrm{ng} / \mathrm{ml})$ at a density of $1 \times 10^{7}$ cells $/ 100-\mathrm{mm}$ dish. After the incubation, the non-adherent cells were collected. The non-adherent cells $\left(1 \times 10^{4}\right.$ cells/well in 96 -well plates $)$ were differentiated into bone marrow-derived macrophages (BMMs) by culture with M-CSF $(50 \mathrm{ng} / \mathrm{ml})$ and TGF- $\beta(1 \mathrm{ng} / \mathrm{ml})$ for $3 \mathrm{~d}$. For differentiation into osteoclasts, the culture medium was changed to medium containing RANKL (100 ng/ml) and MCSF $(50 \mathrm{ng} / \mathrm{ml})$ and the cells were cultured for a further $2 \mathrm{~d}$. RAW264 cells, a murine macrophage cell line supplied by the RIKEN Cell Bank (Tsukuba, Japan), were grown in $\alpha$ MEM containing $10 \%$ FBS and passaged every $3 \mathrm{~d}$. The cells were seeded at $4 \times 10^{3}$ cells/well in 96-well plates. After $24 \mathrm{~h}$, additional medium containing RANKL ( $50 \mathrm{ng} / \mathrm{ml})$ was added to each well. Mature osteoclasts (mOCs) possessing actin ring structures were formed from the RAW264 cells $\left(8.5 \times 10^{3}\right.$ cells/well in 96 -well plates) by culture for $4 \mathrm{~d}$ in the presence of RANKL $(50 \mathrm{ng} / \mathrm{ml})$ and PD98059 $(20 \mu \mathrm{M})$, a MAPK kinase inhibitor that is known to increase the formation of TRAP ${ }^{+}$MNCs. ${ }^{16)}$

TRAP Assay Osteoclast formation was evaluated by measuring the TRAP activity and counting the number of $\mathrm{TRAP}^{+}$MNCs. The cells were sequentially fixed with $10 \%$ formaldehyde for $10 \mathrm{~min}$ and ethanol for $1 \mathrm{~min}$, and then dried. The TRAP activity was measured by incubation in $50 \mathrm{~mm}$ citrate buffer ( $\mathrm{pH} 4.6)$ containing $10 \mathrm{~mm}$ tartrate and $5 \mathrm{~mm} p$-nitrophenylphosphate for $30-60 \mathrm{~min}$. The reaction was stopped by adding $0.1 \mathrm{M} \mathrm{NaOH}$, and the TRAP activity was evaluated by measuring the absorbance at $410 \mathrm{~nm}$ using a microplate reader (Dainippon Sumitomo Pharma Co. Ltd., Osaka, Japan). ${ }^{17)}$ TRAP staining was performed as described previously. ${ }^{17)} \mathrm{TRAP}^{+} \mathrm{MNCs}$ with three or more nuclei were counted.

Viability Assay Cell viability was evaluated using a sodium 3'-[1-(phenylaminocarbonyl)-3,4-tetrazolium]-bis(4methoxy-6-nitro)benzene sulfonic acid hydrate (XTT) assay kit (Roche Diagnostics, Mannheim, Germany). The absorption was measured at $450 \mathrm{~nm}$ using a microplate reader.

Actin Ring Staining $\mathrm{mOCs}$ with actin rings were incubated with or without compounds for various times. The actin rings in the mOCs were stained with Alexa Fluor 488conjugated phalloidin in the dark and then washed with cold phosphate-buffered saline (PBS). The distribution of the actin rings in the mOCs was visualized under a fluorescence microscope (Nikon).

DAPI Staining Cells were fixed with 10\% formalin in PBS for $15 \mathrm{~min}$ at room temperature, and then incubated with $1 \mu \mathrm{g} / \mathrm{ml}$ DAPI in PBS for $30 \mathrm{~min}$. Cells showing fragmented chromatin were considered apoptotic. The distribution of DAPI staining in mOCs was visualized under a fluorescence microscope (Nikon).

Pit Formation Assay BMCs $\left(2 \times 10^{7}\right.$ cells $)$ were cocultured with the stromal/osteoblastic cell line UAMS-32 $2^{18,19}$ $\left(1 \times 10^{6}\right.$ cells $)$ on $100-\mathrm{mm}$ diameter collagen-coated culture dishes in the presence of $1 \alpha, 25$ dihydroxyvitamin $\mathrm{D}_{3}(1 \alpha, 25-$ $\left.(\mathrm{OH})_{2} \mathrm{D}_{3}\right)(10 \mathrm{~nm})$ and prostaglandin E2 $(1 \mu \mathrm{M})$ for $6 \mathrm{~d}$. UAMS-32 cells were kindly provided by Dr. Charles A. O'Brien (University of Arkansas for Medical Sciences). To obtain bone-resorbing mOCs, the cocultured cells were detached by treatment with $0.2 \%$ collagenase at $37^{\circ} \mathrm{C}$ for $10 \mathrm{~min}$, and then cultured on dentin slices in 96-well plates with or without honokiol for $24 \mathrm{~h}$. After the incubation, the cells were removed and the resorption pits were stained with $1 \%$ toluidine blue solution. Images of the resorbed pits were obtained under a light microscope (Nikon).

Western Blotting RAW264 cells $\left(1 \times 10^{6}\right.$ cells/well in 6well plates) were pretreated with honokiol and then stimulated with RANKL for $0,5,15$ or $30 \mathrm{~min}$. The cells were washed with PBS and lysed with ice-cold lysis buffer comprising $50 \mathrm{~mm}$ Tris- $\mathrm{HCl}$ (pH 7.5), 1 mм EDTA, 1 mм EGTA, $1 \%$ TritonX-100, $10 \mathrm{~mm} \beta$-glycerophosphate, $1 \mathrm{~mm}$ sodium vanadate, $50 \mathrm{~mm} \mathrm{NaF}, 0.27 \mathrm{M}$ sucrose, $1 \mathrm{~mm}$ DTT, $1 \mathrm{~mm}$ phenylmethylsulfonyl fluoride and $1 \mathrm{mg} / \mathrm{ml}$ Pefabloc SC (protease inhibitor; Roche Diagnostics). The lysates were centrifuged at $12000 \mathrm{rpm}$ for $10 \mathrm{~min}$ at $4{ }^{\circ} \mathrm{C}$ and the supernatants were collected as protein samples. The concentrations of the protein samples were determined using the Bradford method (Bio-Rad Laboratories, Hercules, CA, U.S.A.). Equal amounts of protein were added to $5 \times$ Laemmli sample loading buffer, followed by boiling for $5 \mathrm{~min}$. Next, the proteins were separated by sodium dodecyl sulfate-polyacrylamide gel electrophoresis (SDS-PAGE) and transferred to polyvinylidene difluoride membranes (Hybond-P; GE Healthcare) by electroblotting. The membranes were blocked with $3 \%$ skim milk in $50 \mathrm{~mm}$ Tris- $\mathrm{HCl}(\mathrm{pH} 7.5), 150 \mathrm{~mm}$ $\mathrm{NaCl}$ and $0.1 \%$ Tween 20 for $30 \mathrm{~min}$ at room temperature, and then incubated with a primary antibody overnight at $4{ }^{\circ} \mathrm{C}$. For detection, the membranes were incubated with a horseradish peroxidase-conjugated secondary antibody for $1 \mathrm{~h}$ at room temperature. Antigen-antibody complexes were visualized with an ECL Western Blot Detection Kit (GE Healthcare) according to the manufacturer's instructions. The membranes were then stripped with a stripping buffer (Restore $^{\mathrm{TM}}$ Western Blot Stripping Buffer; Pierce, Rockford, IL, U.S.A.) and re-probed with another primary antibody.

Statistical Analysis All data were expressed as the means for each series of experiments \pm the standard error of the mean (S.E.M.). The data were analyzed by Student's $t$ test or ANOVA followed by a post hoc Dunnett's test. All statistical analyses were performed using SPSS software ver. 17.0 (SPSS Inc., Chicago, IL, U.S.A.). 


\section{RESULTS}

Honokiol Inhibits Osteoclast Differentiation of BMMs and RAW264 Cells Honokiol inhibited the formation of M-CSF and RANKL-induced TRAP-positive mononuclear and multinuclear osteoclasts by BMMs (Fig. 2A). The MCSF and RANKL-induced increase in TRAP activity was suppressed by treatment with honokiol in a dose-dependent
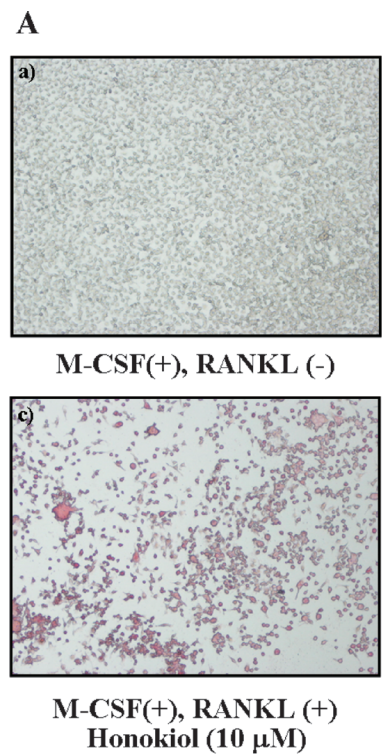

B

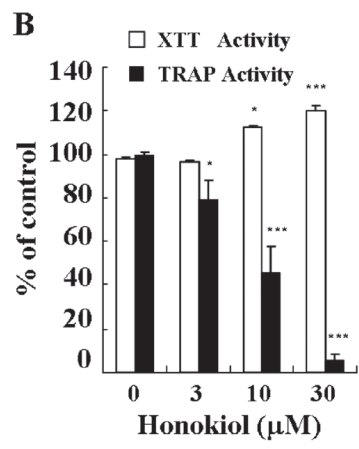

D

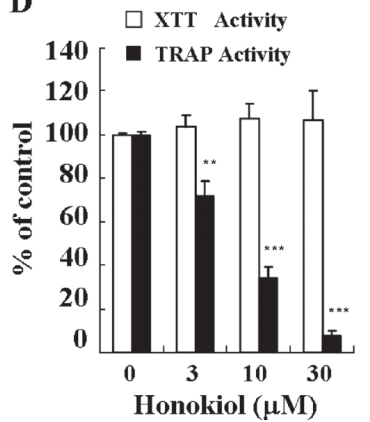

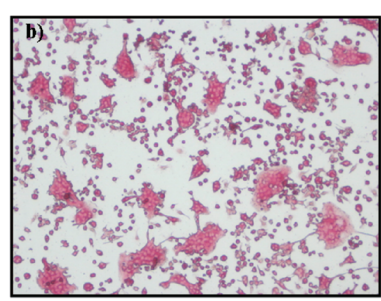
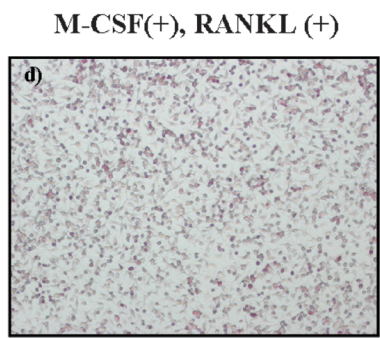

M-CSF $(+)$, RANKL $(+)$ Honokiol $(30 \mu \mathrm{M})$

C

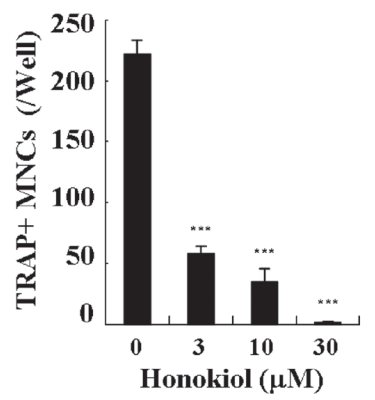

E

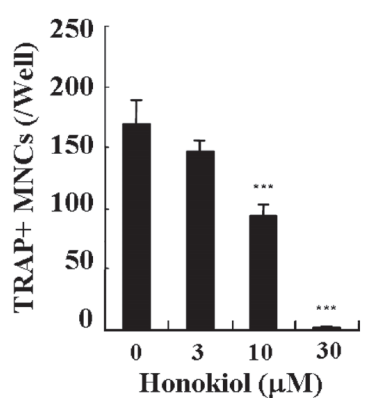

Fig. 2. Honokiol Inhibits RANKL-Induced Osteoclastogenesis in BMMs and RAW264 Cells

BMMs were induced by TGF- $\beta(1 \mathrm{ng} / \mathrm{ml})$ and M-CSF $(50 \mathrm{ng} / \mathrm{ml})$ for $3 \mathrm{~d}$, and then cultured in the presence of RANKL $(100 \mathrm{ng} / \mathrm{ml})$ and M-CSF $(50 \mathrm{ng} / \mathrm{ml})$ with or without honokiol for $2 \mathrm{~d}$. After the culture, the cells were stained for TRAP and photographed $(4 \times)(A)$. Cell viability was determined by the XTT assay and TRAP activity was measured (B). TRAP-positive MNCs containing more than three nuclei were counted among the BMMs (C). RAW264 cells were cultured in the presence of RANKL $(50 \mathrm{ng} / \mathrm{ml})$ with or without honokiol for $3 \mathrm{~d}$. Cell viability was determined by the XTT assay and TRAP activity was measured (D). TRAP-positive MNCs containing more than three nuclei were counted among the RAW264 cells (E). Data are expressed as the mean \pm S.E.M. of at least three cultures. The data were analyzed by ANOVA followed by a post hoc Dunnett's test. $* p<0.05, * * p<0.01$, *** $p<0.001$, vs. control cells.

manner, without showing any cytotoxicity (Fig. 2B). The $\mathrm{IC}_{50}$ value for the TRAP activity was $8.4 \mu \mathrm{m}$. Honokiol also reduced the number of $\mathrm{TRAP}^{+} \mathrm{MNCs}$, and the number was decreased by more than $70 \%$ in the presence of $3 \mu \mathrm{M}$ honokiol (Fig. 2C). Next, we examined the effect of honokiol on osteoclastogenesis by RAW264 cells, which can be induced to differentiate into osteoclasts by treatment with RANKL alone. Honokiol inhibited both the TRAP activity and $\mathrm{TRAP}^{+} \mathrm{MNC}$ formation in RAW264 cells (Figs. 2D, E), similar to the findings for BMMs. These results indicate that the inhibitory effect of honokiol on osteoclastogenesis is correlated with RANKL-induced signaling pathways but not MCSF-induced signaling pathways. The $\mathrm{IC}_{50}$ values for TRAP activity and TRAP ${ }^{+} \mathrm{MNC}$ formation in RAW264 cells were 6.2 and $12 \mu \mathrm{M}$, respectively (Figs. 2D, E). However, honokiol had no effect on the cell viability (Fig. 2D).

Honokiol Inhibits RANKL-Induced Phosphorylation of MAPKs (p38 MAPK, ERK and JNK) and Expressions of c-Fos and NFATc1 To define the molecular mechanism by which honokiol inhibits osteoclast differentiation, we examined the effects of honokiol on RANKL-induced phosphorylation of MAPKs (p38 MAPK, ERK and JNK), which are known to play crucial roles in the expression of osteoclast-specific genes. ${ }^{1,20)}$ In RAW264 cells, the phosphorylation of MAPKs induced by RANKL $(100 \mathrm{ng} / \mathrm{ml})$ reached the maximum levels at $15 \mathrm{~min}$, and decreased thereafter (Fig. $3 \mathrm{~A})$. The presence of honokiol resulted in prominent reductions in the MAPK phosphorylation (Fig. 3A). The RANKLinduced phosphorylation of the MAPKs at $15 \mathrm{~min}$ was dosedependently inhibited by honokiol (Fig. 3B). NF- $\kappa$ B, which is a key transcription factor for osteoclastogenesis, is activated by RANKL via the I $\kappa \mathrm{B}$ kinase (IKK)-I $\kappa \mathrm{B}$ signaling pathway. ${ }^{1,20)}$ Honokiol showed slight repression of RANKLinduced $\mathrm{I} \kappa \mathrm{B}$ degradation at $15 \mathrm{~min}$ (Figs. 3A, B). Activated MAPK signaling pathways are known to induce the expressions of c-Fos and NFATc1, which are essential for RANKLinduced osteoclast differentiation. ${ }^{1,20-22)}$ Therefore, we examined the effects of honokiol on the expressions of c-Fos and NFATc1 proteins in RAW264 cells. Honokiol decreased the expressions of both c-Fos and NFATc1 at the protein level (Fig. 4).

Honokiol Induces Disruption of the Actin Ring Structure in mOCs and Inhibits Bone Resorption Actin rings are distinctive cytoskeletal structures in mOCs and their formation is essential for bone resorption by mOCs. When mOCs with actin rings were treated with honokiol for $24 \mathrm{~h}$, the sizes of the mOCs were constricted and their actin rings were disrupted (Figs. 5A, B). The number of mOCs with actin rings was decreased by honokiol in a dose-dependent manner (Fig. 5D). To determine whether honokiol induces apoptosis, nuclear condensation and fragmentation were assessed by DAPI staining. The results revealed that honokiol did not induce nuclear condensation or fragmentation in mOCs (Fig. 5C) ${ }^{23)}$ After treatment with honokiol for only $12 \mathrm{~h}$, the number of mOCs with actin rings was decreased by more than $70 \%$ (Fig. 5E). Further incubation with honokiol induced an additional decrease in the number of mOCs possessing actin rings (Fig. 5E). Withdrawal of honokiol subtly restored the actin ring structure in mOCs (Fig. 5E). These results suggest that honokiol induces the destruction of actin rings in mOCs within $12 \mathrm{~h}$ and that the effect is largely main- 

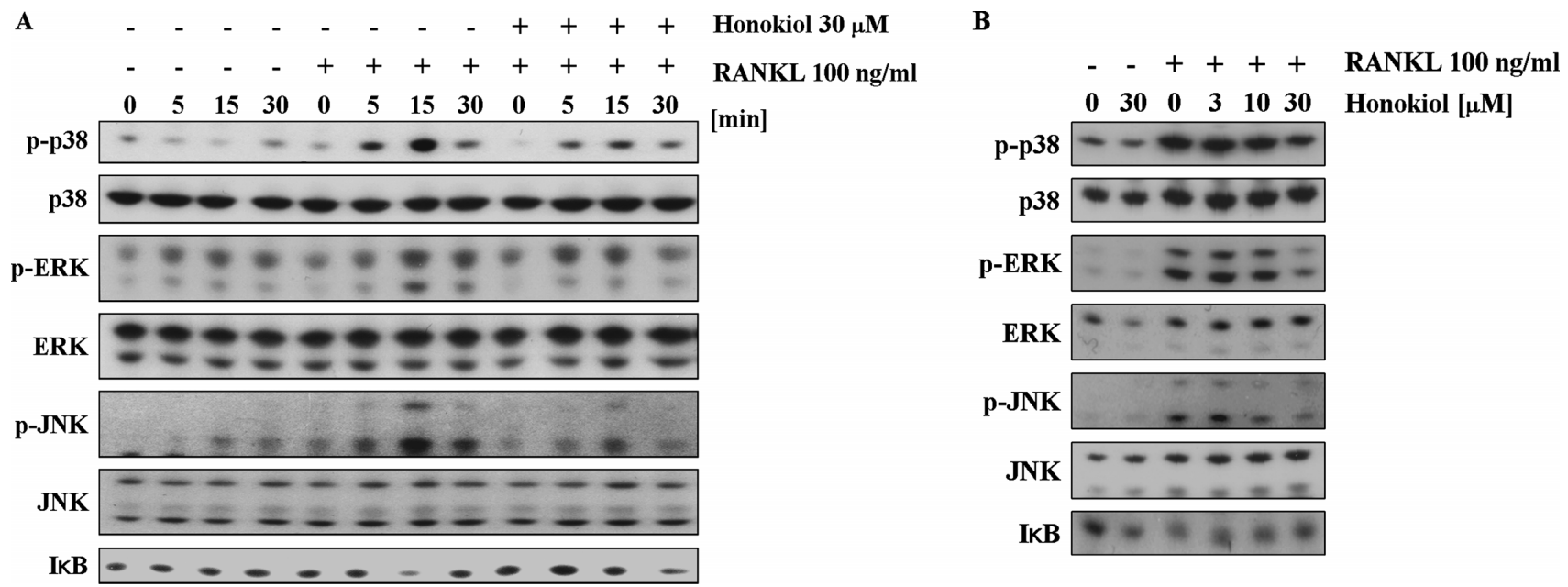

Fig. 3. Honokiol Suppresses RANKL-Induced Phosphorylation of MAPKs (p38 MAPK, ERK and JNK)

RAW264 cells were preincubated in the presence of honokiol for $1 \mathrm{~h}$ and then treated with RANKL (100 ng/ml) for the indicated times. Cell lysates were collected and separated by $10 \%$ SDS-PAGE. The levels of phosphorylated and non-phosphorylated p38 MAPK, ERK, JNK and I $\kappa$ B were determined by Western blotting (A). RAW264 cells were preincubated with or without honokiol for $1 \mathrm{~h}$ and then treated with RANKL $(100 \mathrm{ng} / \mathrm{ml})$ for $15 \mathrm{~min}$. The levels of phosphorylated and non-phosphorylated p38 MAPK, ERK, JNK and $\mathrm{I} \kappa \mathrm{B}$ were determined by Western blotting (B). The results shown are representative of three independent experiments.

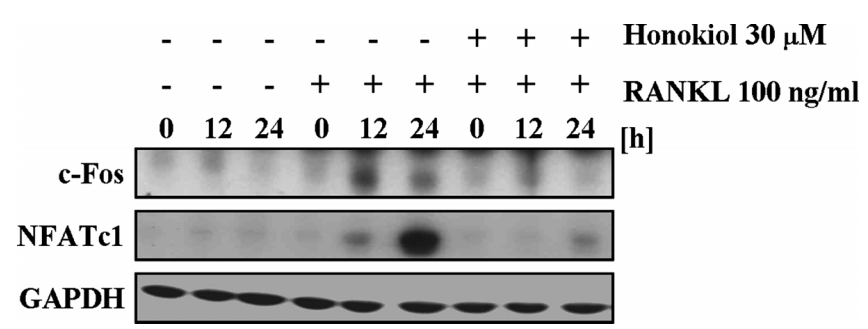

Fig. 4. Honokiol Suppresses RANKL-Induced c-Fos and NFATc1 Expressions

RAW264 cells were cultured in the presence of RANKL $(50 \mathrm{ng} / \mathrm{ml})$ and honokiol $(30 \mu \mathrm{M})$ for the indicated times. Cell lysates were separated by $10 \%$ SDS-PAGE and analyzed by Western blotting with anti-c-Fos, anti-NFATc1 and anti-GAPDH antibodies. The results shown are representative of three independent experiments.

tained even after honokiol is removed.

Next, we investigated the effect of honokiol on osteoclastic bone resorption on dentin slices. Mature osteoclasts were prepared using a previously described coculture system for BMCs and the osteoblast cell line UAMS-32. ${ }^{18,19)}$ When mOCs were cultured on dentin slices, resorption pits were formed in control cultures but suppressed by honokiol treatment (Fig. 6A). The number of resorption pits was markedly reduced in the presence of honokiol $(30 \mu \mathrm{M})$ (Fig. 6B). These results suggest that honokiol induces disruption of the actin rings in mOCs, thereby inhibiting osteoclastic bone resorption without affecting cell survival.

\section{DISCUSSION}

In the present study, we found that honokiol inhibits osteoclast differentiation and function. The inhibitory effect of honokiol on osteoclast differentiation results from the suppression of RANKL-induced MAPK phosphorylation and cFos and NFATc1 expressions. In addition, honokiol directly induces disruption of the cytoskeletal actin rings in mOCs, thereby inhibiting their bone resorption. These findings suggest that honokiol suppresses bone resorption through both its inhibitory effect on osteoclast differentiation and its dis- ruptive effect on the actin rings in mOCs.

Honokiol, a neolignan derived from cinnamic acid, is known as an active component of kouboku, which is used in traditional Chinese medicine. Honokiol is reported to have various activities, including anti-oxidative, anti-inflammatory, anti-allergic, anti-angiogenic and anti-tumor properties. ${ }^{10-15)}$ Previous reports have shown that honokiol inhibits nitric oxide production by lipopolysaccharide-activated RAW264 cells ${ }^{24)}$ and mouse macrophages. ${ }^{25)}$ Recently, honokiol has been shown to potentiate TNF- $\alpha$-induced apoptosis in chronic myelogenous leukemia KBM5 cells, suppress TNF- $\alpha$-induced tumor cell invasion, and inhibit RANKLinduced osteoclastogenesis in RAW264 cells, although the mechanism of action of honokiol on osteoclastogenesis remains unclear. ${ }^{26)}$ In the present study, we have shown that honokiol inhibits M-CSF and RANKL-induced osteoclast differentiation not only in RAW264 cells but also in BMMs. The effects of honokiol on RANKL-induced signaling pathways were examined to clarify the mechanism of its inhibitory action on osteoclastogenesis. RANKL-RANK signal transduction stimulates TNF receptor-associated factors (TRAFs), MAPKs and transcription factors (NFATc1, activator protein-1 (AP-1) and NF- $\kappa \mathrm{B}$ ), which are known to play critical roles in osteoclast differentiation, activation and survival. ${ }^{1,27)}$ Our results have demonstrated that honokiol suppresses RANKL-evoked expression of c-Fos and subsequent induction of NFATc1, which are key transcription factors for osteoclast differentiation, ${ }^{27)}$ and that honokiol inhibits RANKL-induced MAPK phosphorylation. Recent studies have reported that MAPKs are important for the induction of c-Fos and NFATc1 during osteoclast differentiation. ${ }^{1,20,21,27,28)}$ Therefore, honokiol could inhibit the expressions of c-Fos and NFATc1 through its suppression of RANKL-induced phosphorylation of MAPKs in RAW264 cells. Honokiol is known to inhibit TNF- $\alpha$-stimulated NF- $\kappa \mathrm{B}$ activation through suppression of IKK activation. ${ }^{15,26)}$ In our study, honokiol showed only slight suppression of the $\mathrm{I} \kappa \mathrm{B}$ degradation induced by RANKL in RAW264 cells. This observation means that suppression of the MAPK/c-Fos/NFATc1 path- 

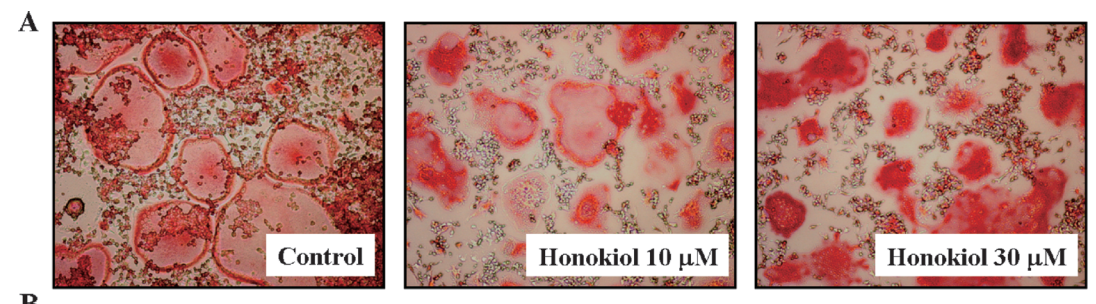

B
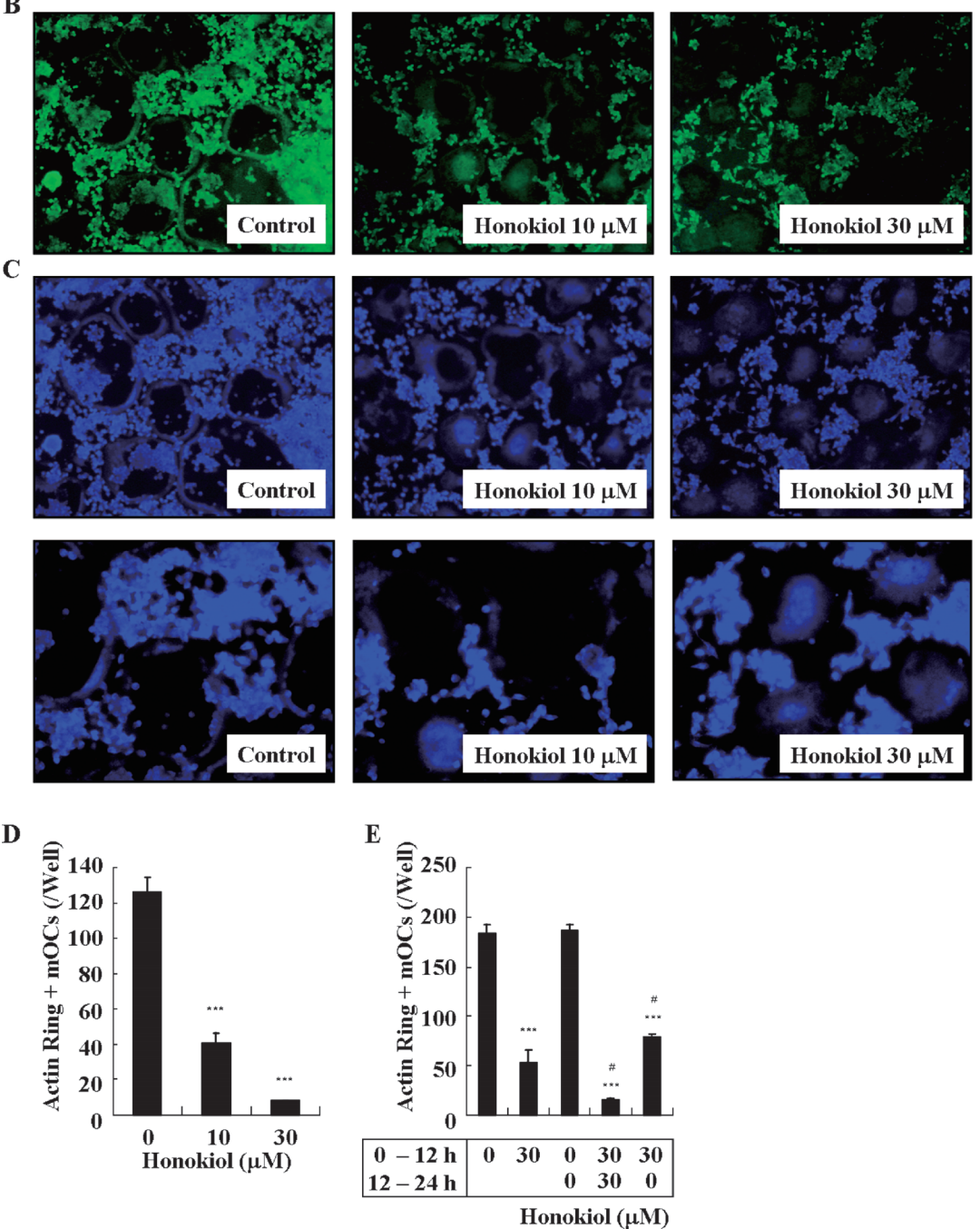

Fig. 5. Honokiol Induces Disruption of the Actin Rings in mOCs

RAW264 cells $\left(8.5 \times 10^{3}\right.$ cells/well in 96-well plates) were cultured with RANKL ( $\left.50 \mathrm{ng} / \mathrm{ml}\right)$ and PD98059 $(20 \mu \mathrm{M})$ for $4 \mathrm{~d}$. mOCs with actin rings were treated with honokiol $(10$ or $30 \mu \mathrm{M})$ in the presence of RANKL and PD98059 for $24 \mathrm{~h}$. After fixation, the cells were stained for TRAP (10X) (A), incubated with Alexa Fluor 488 -conjugated phalloidin $(10 \times)(B)$ or stained with DAPI (upper panels: $10 \times$; lower panels: $20 \times)($ C). The numbers of mOCs possessing clear actin rings were counted as the means \pm S.E.M. of at least three cultures (D). mOCs with actin rings were treated with honokiol $(30 \mu \mathrm{M})$ in the presence of RANKL and PD98059 for $12 \mathrm{~h}$, and then cultured in the presence of RANKL and PD98059 with or without honokiol for $12 \mathrm{~h}(\mathrm{E})$. The data were analyzed by ANOVA followed by a post hoc Dunnett's test. $* * * p<0.001, v s$. control cells; \# $p<0.05, v s$. cells treated with honokiol for only $12 \mathrm{~h}$.

A

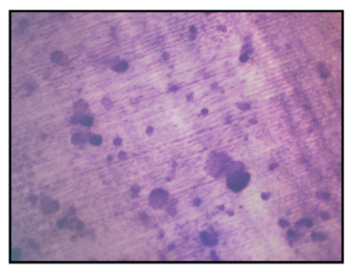

Control

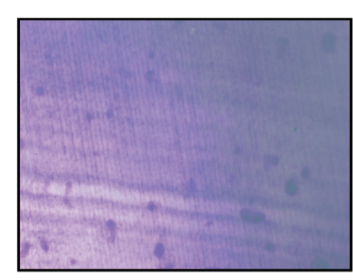

Honokiol $(30 \mu \mathrm{M})$

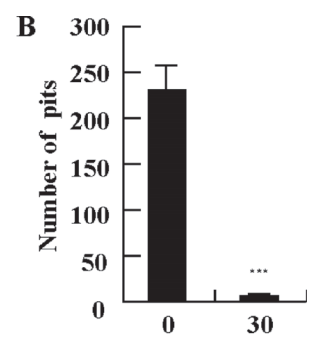

Honokiol $(\mu \mathrm{M})$

Fig. 6. Honokiol Inhibits Resorption Pit Formation

BMCs $\left(2 \times 10^{7}\right.$ cells $)$ were cocultured with stromal/osteoblastic cell line UAMS-32 cells $\left(1 \times 10^{6}\right.$ cells $)$ in collagen-coated 100 -mm culture dishes in the presence of $1 \alpha, 25-$ $(\mathrm{OH})_{2} \mathrm{D}_{3}(10 \mathrm{nM})$ and prostaglandin E2 $(1 \mu \mathrm{M})$ for $6 \mathrm{~d}$. Differentiated osteoclasts were peeled off and plated on dentin slices in 96 -well plates. The cells were then cultured with or without honokiol for $24 \mathrm{~h}$. Resorption pits were stained with $1 \%$ toluidine blue and photographed (10×) (A). The numbers of resorption pits were counted as the means \pm S.E.M. of at least three cultures (B). The data were analyzed by Student's $t$-test. $* * * p<0.001, v s$. control cells. 
ways, but not the $\mathrm{I} \kappa \mathrm{B} / \mathrm{NF}-\kappa \mathrm{B}$ pathways, is important for the effect of honokiol on osteoclast differentiation and that the inhibitory mechanism of honokiol on RANKL-induced osteoclastogenesis may differ from that in TNF- $\alpha$-induced events such as the expressions of proinflammatory cytokines and tumor cell invasion. ${ }^{15,26)}$

Activated osteoclasts exhibit polarized cytoskeletal structures called actin rings and their formation is important for bone resorption. ${ }^{29)}$ Honokiol acts directly on mOCs and induces the disruption of their actin rings. The disruption of the actin rings in mOCs was induced by honokiol within $12 \mathrm{~h}$ and mostly continued up to $24 \mathrm{~h}$, even after the withdrawal of honokiol. Honokiol also suppressed the resorption pit formation by mOCs on dentin slices. Many reports have shown that honokiol induces apoptosis in several types of cancer cells. $^{26,30-33)}$ In our study, honokiol suppressed RANKL-induced phosphorylation of ERK, which is known to regulate osteoclast survival, ${ }^{1,34)}$ in osteoclast precursor RAW264 cells. However, honokiol did not affect the cell proliferation of RAW264 cells or induce apoptosis in mOCs. These observations indicate that honokiol specifically causes apoptosis in certain cell types. Taken together, these results suggest that honokiol directly induces the disruption of the actin rings in mOCs, and inhibits bone resorption without affecting $\mathrm{mOC}$ survival.

In conclusion, we have demonstrated that honokiol suppresses osteoclast differentiation by inhibiting RANKL-induced signaling pathways and attenuates bone resorption by disrupting the actin rings in mOCs. Honokiol could be useful for the treatment of bone diseases associated with excessive bone resorption. Further studies, such as the identification of target molecules of honokiol and clarification of its effects on animal models, are required.

Acknowledgments We thank Dr. Charles A. O'Brien (University of Arkansas for Medical Sciences) for providing UAMS-32 cells. This work was partly supported by a Grantin-Aid for Scientific Research from the Japanese Ministry of Education, Culture, Sports, Science and Technology. This study was performed at a laboratory supported by an endowment from Erina Co., Inc.

\section{REFERENCES}

1) Boyle W. J., Simonet W. S., Lacey D. L., Nature (London), 423, 337342 (2003).

2) Suda T., Takahashi T., Martin T. J., Endocr. Rev., 13, 66-80 (1992).

3) Yasuda H., Shima N., Nakagawa N., Yamaguchi K., Kinosaki M., Mochizuki S., Tomoyasu A., Yano K., Goto M., Murakami A., Tsuda E., Morinaga T., Higashio K., Udagawa N., Takahashi N., Suda T., Proc. Natl. Acad. Sci. U.S.A., 95, 3597-3602 (1998).

4) Lancey D. L., Timms E., Tan H. L., Kelley M. J., Dunstan C. R., Burgess T., Elliott R., Colombero A., Elliott G., Scully S., Hsu H., Sullivan J., Hawkins N., Davy E., Capparelli C., Eli A., Qian Y. X., Kaufman S., Sarosi I., Shalhoub V., Senaldi G., Guo J., Delaney J., Boyle W. J., Cell, 93, 165-176 (1998).

5) Hsu H., Lacey D. L., Dunstan C. R., Solovyev I., Colombero A., Timms E., Tan H. L., Elliott G., Kelley M. J., Sarosi I., Wang L., Xia X. Z., Elliott R., Chiu L., Black T., Scully S., Capparelli C., Morony S., Shimamoto G., Bass M. B., Boyle W. J., Proc. Natl. Acad. Sci.
U.S.A., 96, 3540-3545 (1999).

6) Wani M. R., Fuller K., Kim N. S., Choi Y., Chambers T., Endocrinology, 140, 1927-1935 (1999).

7) Matsumoto M., Sudo T., Saito T., Osada H., Tsujimoto M., J. Biol. Chem., 275, 31155-31161 (2000).

8) Meiyanto E., Hoshijima M., Ogawa T., Ishida N., Takeya T., Biochem. Biophys. Res. Commun., 282, 278-283 (2001).

9) Fujita M., Itokawa H., Sashida Y., Yakugaku Zasshi, 93, 429-434 (1973).

10) Munroe M. E., Arbiser J. L., Bishop G. A., J. Immunol., 179, 753763 (2007).

11) Hamasaki Y., Muro E., Miyanji S., Yamamoto S., Kobayashi I., Sato R., Zaitu M., Matsuo M., Ichimaru T., Tasaki H., Miyazaki S., Int. Arch. Allergy Immunol., 110, 278-281 (1996).

12) Pyo M. K., Lee Y., Yun-Choi H. S., Arch. Pharm. Res., 25, 325-328 (2002).

13) Bai X., Cerimele F., Ushio-Fukai M., Waqas M., Campbell P. M., Govindarajan B., Der C. J., Battle T., Frank D. A., Ye K., Murad E., Dubiel W., Soff G., Arbiser J. L., J. Biol. Chem., 278, 35501-35507 (2003).

14) Lee J., Jung E., Park J., Jung K., Lee S., Hong S., Park J., Park E., Kim J., Park S., Park D., Planta Med., 71, 338-343 (2005).

15) Tse A. K., Wan C. K., Shen X. L., Yang M., Fong W. F., Biochem. Pharmacol., 70, 1443-1457 (2005).

16) Hotokezaka H., Sakai E., Kanaoka K., Saito K., Matsuo K., Kitaura H., Yoshida N., Nakayama K., J. Biol. Chem., 277, 47366-47372 (2002).

17) Woo J. T., Nakagawa H., Notoya M., Yonezawa T., Udagawa N., Lee I. S., Ohnishi M., Hagiwara H., Nagai K., Biol. Pharm. Bull., 27, 504 509 (2004).

18) O’Brien C. A., Gubrij I., Lin S. C., Saylors R. L., Manolagas S. C., J. Biol. Chem., 274, 19301-19308 (1999).

19) Yamada A., Takami M., Kawawa T., Yasuhara R., Zhao B., Mochizuki A., Miyamoto Y., Eto T., Yasuda H., Nakamichi Y., Kim N., Katagiri T., Suda T., Kamijo R., Immunology, 120, 573-579 (2007).

20) Lee Z. H., Kim H. H., Biochem. Biophys. Res. Commun., 305, $211-$ 214 (2003).

21) Huang H., Chang E. J., Ryu J., Lee Z. H., Lee Y., Kim H. H., Biochem. Biophys. Res. Commun., 351, 99-105 (2006).

22) Kamel Mohamed S. G., Sugiyama E., Shinoda K., Hounoki H., Taki H., Maruyama M., Miyahara T., Kobayashi M., Biochem. Biophys. Res. Commun., 329, 839-845 (2005).

23) Kwak H. B., Lee S. W., Li Y. J., Kim Y. A., Han S. Y., Jhon G. J., Kim H. H., Lee Z. H., Biochem. Pharmacol., 67, 1239-1248 (2004).

24) Son H. J., Lee H. J., Yun-Choi H. S., Ryu J. H., Planta Med., 66, $469-471$ (2000).

25) Matsuda H., Kageura T., Oda M., Morikawa T., Sakamoto Y., Yoshikawa M., Chem. Pharm. Bull., 49, 716-720 (2001).

26) Ahn K. S., Sethi G., Shishodia S., Sung B., Arbiser J. L., Aggarwal B. B., Mol. Cancer Res., 4, 621-633 (2006).

27) Wagner E. F., Eferl R., Immunol. Rev., 208, 126-140 (2005).

28) Takayanagi H., Nat. Rev. Immunol., 7, 292-304 (2007).

29) Gohda J., Akiyama T., Koga T., Takayanagi H., Tanaka S., Inoue J., EMBO J., 24, 790-799 (2005).

30) Yang S. E., Hsieh M. T., Tsai T. H., Hsu S. L., Biochem. Pharmacol., 63, 1641-1651 (2002).

31) Ishitsuka K., Hideshima T., Hamasaki M., Raje N., Kumar S., Hideshima H., Shiraishi N., Yasui H., Roccaro A. M., Richardson P., Podar K., Le Gouill. S., Chauhan D., Tamura K., Arbiser J., Anderson K. C., Blood, 106, 1794-800 (2005).

32) Shigemura K., Arbiser J. L., Sun S. Y., Zayzafoon M., Johnstone P. A., Fujisawa M., Gotoh A., Weksler B., Zhau H. E., Chung L. W., Cancer, 109, 1279-1289 (2007).

33) Garcia A., Zheng Y., Zhao C., Toschi A., Fan J., Shraibman N., Brown H. A., Bar-Sagi D., Foster D. A., Arbiser J. L., Clin. Cancer Res., 14, 4267-4274 (2008).

34) Miyazaki T., Katagiri H., Kanegae Y., Takayanagi H., Sawada Y., Yamamoto A., Pando M. P., Asano T., Verma I. M., Oda H., Nakamura K., Tanaka S., J. Cell Biol., 148, 333-342 (2000). 